\title{
Pembelajaran SOLE dalam Membangun Keefektifan Belajar pada Peserta Didik
}

\author{
Aura Fariha $\left({ }^{1}\right)$, Nur Amalia $\left({ }^{2}\right)$ \\ Program Studi Pendidikan Bahasa dan Sastra Indonesia, Universitas Muhammadiyah Prof Dr. Hamka $\left({ }^{1}\right)$ \\ Program Studi Pendidikan Bahasa dan Sastra Indonesia, Universitas Muhammadiyah Prof Dr. Hamka $\left({ }^{2}\right)$ \\ Email: aurafariha@gmail.com $\left({ }^{1}\right)$, nur21amalia@gmail.com $\left({ }^{2}\right)$
}

Riwayat artikel: submit: 16 Juli 2021 ; revisi: 23 September 2021, diterima: 30 September 2021

\begin{abstract}
ABSTRAK
Tujuan dari penulisan ini ialah untuk membangun keefektifan pembelajaran pada peserta didik melalui model pembelajaran SOLE (Self Organizing Learning Environment). Pada masa pandemic Covid-19, system konsep pembelajaran diubah menjadi daring (Online) untuk tetap berjalan proses pembelajaran dan tersampaikan kepada peserta didik dengan maksimal. Melalui pembelajaran daring (Online) atau BDR (Belajar Dari Rumah) atau PJJ (Pembelajaran Jarak Jauh) peserta didik tetap bisa mengakses pembelajaran secara sempurna dan tercapainya indikator kompetensi. Hambatan dalam pembelajaran daring (Online) banyak dihadapin oleh orang tua tersebab dengan kemandirian pada anak (peserta didik) dan dalam mengikuti pembelajaran daring (Online). Solusi yang didapat dari analisis ini ialah dengan menanamkan model pembelajaran SOLE (Self Organizing Learning Environment) yang menitik beratkan kemandirian pada setiap peserta didik. Model pembelajaran SOLE ini mempunyai tujuan dalam membentuk kemampuan pada peserta didik, diantaranya 1. Keahlian berpikir kritis 2 . Keahlian memecahkan masalah 3. Keahlian berkomunikasi, serta pada model pembelajaran SOLE terdapat tiga tahap aktifitas pembelajaran : 1. Pertanyaan 2. Investigasi 3. Mengulas dari ketiga tahap aktifitas tersebut dapat menciptakan kefektifan peserta didik dalam menerima materi. Dengan menanamkan pembelajaran model SOLE (Self Organizing Learning Environment) sangat membantu dalam proses pembelajaran dari rumah secara (Online) peserta didik peran utama untuk aktif dalam setiap pembelajaran dan menanamkan sikap mandiri serta keefektifan belajar pada peserta didik.
\end{abstract}

Kata kunci: Peserta didik, Pembelajaran daring, Model SOLE

\section{ABSTRACT}

The purpose of this paper is to build the effectiveness of learning in students through the SOLE (Self Organizing Learning Environment) learning model. During the Covid-19 pandemic, the learning concept system was changed to online (Online) to keep the learning process running and conveyed to students optimally. Through online learning (Online) or BDR (Learning from Home) or PJJ (Distance Learning) students can still access learning perfectly and achieve competency indicators. Many parents face obstacles in online learning due to independence in children (students) and in participating in online learning (Online). The solution obtained from this analysis is to embed the SOLE (Self Organizing Learning Environment) learning model which emphasizes the independence of each student. This SOLE learning model has a goal in forming competencies (skills) in students, including 1. Critical thinking 2. Problem solving ability 3. Communication skills, and in the SOLE learning model there are three stages of learning activities: 1. Questions 2. Investigation 3. Reviewing the three stages of the activity can create the effectiveness of students in receiving the material. By embedding learning the SOLE (Self Organizing Learning Environment) model is very helpful in the learning process from home (Online) students have the main role to be active in every learning and instill an independent attitude and learning effectiveness in students.

Keywords: Students, Online learning, SOLE . Model 
Fahira.A; Amalia.N (2021). Pembelajaran SOLE dalam Membangun Keefektifan Belajar pada Peserta Didik. Edudikara: Jurnal Pendidikan dan Pembelajaran, 6(3), 152-157.

\section{PENDAHULUAN}

Pembelajaran ialah sebuah proses ilmu pengetahuan tersimpan pada diri manusia. Proses tersebut terdapat aktivitas peserta didik sebagai seorang murid dan ada seorang guru sebagai pembelajar. Proses pembelajaran ini dilaksankan melalui tahap perencanaan, pelaksanaan, dan evaluasi oleh pendidik kemudian diterapkan dengan pertemuan bersama-sama dengan difasilitasi media, alat, dan bahan ajar yang sesuai. Tugas dari seorang guru sebagai seorang pengendali atau pengarah terhadap keterampilan dan pengetahuan yang akan dimiliki oleh peserta didik. Sementara, peserta didik berperan aktif dalam menjalani perintah guru untuk menyelesaikantujuan proses belajar yang akan terlihat dari indikator pencapaian kompetensi pada setiap peserta didik (Syarifudin, 2020).

Konsep belajar biasa dikatakan sebagai belajar sepanjang masa kehidupan. Belajar tidak mengenal waktu,bisa dilasksanakan dimana saja bisa dilakukan oleh setiap manusia insan yang hidup. Dan konsep belajar sepanjang kehidupan menjadikan seseorang tidak boleh ber putus semangat dalam proses belajar walaupun ada rintangan yang datang dalam berbagai wujud. Seperti saaat ini bencana pandemi covid-19 yang tidak seharusnya dijadikan sebagi penghalang dalam belajar, sebab belajar bisa dilakukan setiap saat selagi jiwa masih diberikan kesehatan dan jiwa yang hidup. Pembelajaran saat ini dilakukan secara daring (Online) karena pandemi covid-19. Pembelajaran daring (Online) selama masa pandemi merupakan salah satu kebijakan untuk pembelajaran saat ini. Belajar dari rumah (BDR) pada tingkat sekolah membutuhkan sebuah kolaborasi antara guru, peserta didik, dan orang tua peserta didik (wali murid). Pembelajaran jarak jauh banyak sekali mengalami permaslaahan salah satunyanya pembelajaran yang disampaikan oleh guru, selama daring (Online) system dan model pembelajaran yang digunakan guru berbeda tidak sama seperti pada pembelajaran secara langsung disekolah seperti biasanya. Guru harus memiliki kreatifitas dalam menyusun pembelajaran pada setiap pertemuan pembelajaran pada peserta didik.

Permasalahan belajar secara daring yang dihadapi oleh orang tua dan peserta didik, permaslaahan itu berkaitan dengan kemandirian dan keinginan siswa dalam mengikuti pembelajaran daring (Online), diantaranya : (Firdaus et al., 2021) 1. Peserta didik tidak mau belajar, jika tidak ada tugas 2 . Peserta didik merasa pembelajaran online ini bukan sebuah kegiatan sekolah,3. Peserta didik belum mengerti kegunaan dari mereka belajar daring ini 4. Peserta didik hanya mengumpulkan tugas saja tanpa perlu mengerti pembelajaran yang dibagikan oleh guru, 5. Peserta didik belum bisa merenggangkan waktu extra untuk belajar, 6 . Beberapa peserta didik memilih tugas yang lebih mudah terlebih dahulu dikerjakan, 7. Peserta didik belum bisa membedakan informasi pada pembelajaran sehingga ditemykan kurangnya fakta/analisis dengan sebuah penugasan. Dalam hal ini masalah kemandirian belajar pada siswa berhubungan erat dengan (Self Directing Learning) merupakan peserta didik diikutsertakan dalam mengetahui apa yang akan nantinya untuk dipelajari untuk menjadi acuan dalam menemukan jawaban. Kemandirian belajar pada siswa juga perlu dilatih agar tidak bergantung pada pertolongan orang lain dalam mencapai pemahaman pembelajaran dengan sadar yang dilakukan pada dirinya sendiri.

Pada masa pandemic covid-19 ini, pembelajaran dilaksanakan secara daring (Online) yang mengharuskan seorang guru untuk mencari solusi agar proes pembelajaran tetap berjalan efektif dan pencapaian pemahaman materi kepada siswa tersampaikan. Guru harus mencari solusinya agar peserta didik tetap belajar dengan nyaman dan pencapaian yang didapat maksimal. (Kusasi \& Satui, 2021) Solusi, seorang guru atau pengajar perlu mengubah untuk penyesuaian kepada peserta didik yaitu dengan cara mengajarnya agar peserta didik mampu materi yang disampaikan guru dan tetap bisa melaksanakan kegiatan belajar walaupun di rumah. Model pembelajaran yang bisa diterapkan dalam pembelajaran masa pandemic covid19 ialah SOLE (Self Organizing Learning Environment), model pembelajaran SOLE ialah 
Fahira.A; Amalia.N (2021). Pembelajaran SOLE dalam Membangun Keefektifan Belajar pada Peserta Didik. Edudikara: Jurnal Pendidikan dan Pembelajaran, 6(3), 152-157.

pembelajaran yang fokus dalam pembelajaran secara individu yang dilakukan oleh siapa saja yang ingin belajar dengan laman internet dan perangkat pintar (Smartphone/gadget) yang dimilikinya. Ardzika ( dalam Kusasi \& Satui, 2021). Harapan yang dinginkan pada pembelajaran SOLE (Self Organizing Learning Environment) bisa mewujudkan aktivitas pembelajaran yang efektif, tercapai kemaksimalan pembelajaran, penyampaian materi kepada peserta didik dan menjadi solusi dalam pembelajaran di masa pandemic covid-19.

Berdasarkan penjelasan yang dipaparkan diatas bahwa tujuan dari penulisan ini ialah untuk membangun keefektifan pembelajaran pada peserta didik melalui model pembelajaran SOLE (Self Organizing Learning Environment).

\section{ANALISIS}

\section{Pengertian Model Pembelajaran SOLE (Self Organizing Learning Environment).}

Self Organized Learning Environment (SOLE) ialah model pembelajaran yang diciptakan oleh seorang praktisi pendidikan yang berasal dari India yang bernama Sugata Mitra, la membuat sebuah eksperimen di daerah sub urban New Delhi dengan memasangkan komputer yang terhubung dengan akses internet pada dinding dinding yang ia lubangi, kemudian ditaruh kamera tersembunyi. Komputer ini dimainkan oleh anak-anak kemudian mereka belajar dan saling memberitahu bagaimana cara menggunakannya, yang dapat mereka pelajari pada perangkat tersebut seperti, bahasa Inggris dan penggunaan peramban untuk mengakses situssitus sains. (Nyoman \& Wati, 2021). Model pembelajaran SOLE (Self Organized Learning Environments) berfokus pada proses pembelajaran mandiri yang dilakukan siapa saja untuk belajar dengan menggunakan laman internet dan perangkat pintar yang dimilikinya. Model pembelajaran SOLE digunakan untuk mengukur kedalaman kemampuan peserta didik dalam memahami materi secara mandiri.

(Wati, 2020) Model pembelajaran SOLE ini mempunyai tujuan dalam menciptakan kompetensi atau keahlian pada peserta didik. Kompetensi / keahlian yang diharapkan akan tercipta pada diri peserta didik melalu model pembelajaran SOLE ini, diantaranya :

1. Berfikir kreatif. Pada pembelajaran SOLE setiap peserta didik dibentuk untuk melatih rasa keingintahuannya dengan guru memberikan sebuah pertanyaan. Sebab rasa ingin tahu dengan menggunakan akses internet, peserta didik mampu mencari jawaban sendiri terhadap pertanyaan yang diberikan oleh guru.

2. Kemampuan dalam memecahkan masalah mencari solusi. Pada model pembelajaran tersebut, setiap pertanyaan yang diberikna oleh guru pasti memiliki jawaban. Cara peserta didik mencari jawaban memanfaatkan Teknologi Informasi dan Komunikasi (TIK). Lalu, pertanyaan yang diajukan kepada peserta didik, akan membawa peserta didik mendapatkan pengetahuan dan pertanyaan baru.

3. Kemampuan berkomunikasi. Model pembelajaran ini, Setiap jawaban yang didapat tentunya perlu dialihkan kepada peserta didik yang lain. Setiap peserta didik akan diberikan kesempatan menyampaikan pikiran atas jawaban yang ia dapat berdasarkan pemahamannya. Dengan begitu, mampu melatih cara menyampaikan jawaban yang baik dan mampu melatih peserta didik berkomunikasi yang baik.

Pada model pembelajaran SOLE, ada tiga langkah yang harus dilakukan oleh peserta didik. Guru hanya memberikan stimulus dalam bentuk pertanyaan terkait materi yang akan diulas. Tiga tahap aktifitas yang dilaksanakan dalam pembelajaran model SOLE, ialah :

a. Pertanyaan, Guru akan memberikan pertanyaan yang dapat menimbulkan rasa keingintahuan tahu peserta didik pada materi yang akan diajarkan, dari pertanyaan tersebut diharapkan dapat menimbulkan pertanyaan-pertanyaan lain terhadap materi yang akan diajarkan guru. 
Fahira.A; Amalia.N (2021). Pembelajaran SOLE dalam Membangun Keefektifan Belajar pada Peserta Didik. Edudikara: Jurnal Pendidikan dan Pembelajaran, 6(3), 152-157.

b. Investigasi, Guru menyuruh peserta didik untuk membentuk kelompok-kelompok kecil. Peserta didik dalam kelompoknya saling bekerja sama dengan menggunakan perangkat internet untuk mencari jawaban pada pertanyaan yang diberikan oleh guru.

c. Mengulas, Setiap kelompok peserta didik mempresentasikan hasil dari analisis mereka terhadap pertanyaan yang diberikan oleh guru. Tahapan dalam pelaksanaan model pembelajaran SOLE, diantaranya : 1) Memberikan pertanyaan yang berhubungan pada materi yang akan dipelajari nantinya 2) Mengkoordinasikan peserta didik 3) Mengeksplorasi siswa 4) Monitoring 5) Lalu, peserta didik mempresentasi hasil eksplorasi dan inverstigasi kepada teman-temannya 6) dan yang terakhir evaluasi dari hasil presentasi setiap kelompok / peserta didik.

\section{Model Pembelajaran SOLE (Self Organizing Learing Environment) Pada Proses Belajar Dari Rumah (BDR).}

(Saleh, 2020) Mengatakan bahwa bangsa Indonesia sejak awal lahirnya, founding fathers. Indonesia sudah mengerti dimana pendidikan itu sebuah kunci untuk menjadikan bangsa yang merdeka. Dimana bangsa yang maju, peran pendidikan itu endidikan sangat penting, karena dengan pendidikan sumber daya manusia akan terdidik. Dengan pendidikan sebuah bangsa bisa membangun peradaban baru, pengembangan baru yang akan memajukan bangsanya dan sumber daya manusianya, pendidikan akan memperoleh ilmu pengetahuan yang menjadi sumber terbentuknya pemahaman dan pemikiran yang ideal untuk setiap insan manusia dalam meningkatkan pemahaman pada dirinya, jika manusia sudah memiliki akan pemahaman suatu bidang ilmu pengetahuan maka akan mudah untuk tersalurkan dalam mewujudkan gagasangagasan baru dalam menyongsong kehidupan masyarakat yang sejahtera, merata perekonomian yang stabil, serta pendidikan yang menyeluruh yang merupakan sebuah hak warga negara untuk mendapatkan pendidikan yang layak. (Sole \& Anggraeni, 2018) Saat ini pada abad 21 disebut sebagai abad ilmu pengetahuan yang merupakan landasan peradaban untuk berbagai aspek kehidupan. Proses pembelajaran pada abad 21 menekankan kepada kemampuan peserta didik agar dapat berpikir kritis, mampu mengintegrasikan ilmu dengan dunia nyata (realitas), mampu menguasai teknologi infromasi, berkomunikasi, dan bekerja sama.

Dalam mengantarkan peserta didik dalam mencapai ilmu pengetahuan mengikuti jejak perkembangan zaman yang semakin maju, seorang pendidik/guru mampu memberikan pengajaran yang layak dan baik untuk kemajuan proses pembelajaran pada peserta didik dengan pantangan situasi dan kondisi. Pada saat ini, pandemic covid-19 sedang menyelimuti kita semua yang mempengaruhi perubahan segala aspek kehidupan, termasuk pendidikan. (Arifa, 2020) Pada pembelajaran dari rumah dengan PJJ baiknya tetap bisa memenuhi kebutuhan belajar peserta didik untuk meningkatkan bakat dan minat sesuai dengan jenjang pendidikan. Untuk bisa menciptakan hal demikian diperlukan sebuah kesiapan pendidik/guru, kurikulum yang sudah sesuai, ketersediaan sumber belajar yang cukup, serta dukungan jaringan stabil agar komunikasi dengan peserta didik dan dan guru dapat efektif. Namun, dalam proses PJJ,BDR ini masih banyak hambatan yang dihadapi, banyak persiapan yang disusun secara mendadak dan apa adanya. Proses pembelajaran terganggu, sistem pembelajaran pun dirancang dengan mengubah model, metode yang akan disampaikan guru kepada peserta didiknya agar peserta didik dapat tetap memahami materi yang disampaikan walau dalam kondisi pembelajaran jarak jauh dan belajar dari rumah (BDR). Seorang guru harus kreatif didalam kondisi seperti ini, mencari celah untuk tetap bisa mengefektifkan proses pembelajaran agar tetap efektif. Agar peserta didik tetap mendapatkan ilmu pengetahuan maka digunakan sebuah model pembelajaran yang cocok dalam masa BDR (Belajar dari rumah ini) Diantara solusinya ialah dengan metode pembelajaran SOLE (Self Organizing Learnning 
Fahira.A; Amalia.N (2021). Pembelajaran SOLE dalam Membangun Keefektifan Belajar pada Peserta Didik. Edudikara: Jurnal Pendidikan dan Pembelajaran, 6(3), 152-157.

Environment) yang menitik beratkan kepada kemandirian peserta didik dalam belajar. Peserta didik dilatih secara mandiri dalam proses pembelajaran berlangsung, kemandirian peserta didik dilatih dalam system model pembelajaran ini. Pembelajaran dengan menggunakan model SOLE (Self Organizing Learning Environment) dapat menghasilkan peserta didik yang mandiri akan pola pikirnya serta keterampilan yang dimilikinya, sebab peserta didik dituntun untuk berperan aktif dan giat dalam proses pembelajaran agar tercapainya kemaksimalannya indicator pencapaian kompetensi.

Menanamkan Keefektifan Model Pembelajaran Sole (Self Organizing Learning Environment).

(Rosyid \& Ekowanti, 2018) Sugatra Mitra mengatakan SOLE (Self Organized Learning Environment) untuk mengkoordinasikan kegiatan belajar kepada masyarakat secara informal. Guru harus bisa mengambil peran-peran baru dalam pembelajaran.Tugas utamanya adalah mengorganisasikan berbagai ragam SOLE SOLE (Self Organized Learning Environment). SOLE ialah model pembelajaran yang dirangkap untuk membantu tenaga pendidikan atau guru untuk mendorong peserta didik dengan menciptakan rasa ingin tahu yang ada dari dalam diri peserta didik. Kelebihan pembelajaran model SOLE dapat memberikan pengalaman belajar secara mandiri pada peserta didik. Hal ini sangat bersangkut dengan permasalahan di lapangan saat ini BDR (Belajar dari rumah), yaitu peserta didik kurang mempunyai stimulus kemandirian dalam proses belajarnya. Peserta didik lebih kepada mengandalkan orang lain (Orang tua atau anggota keluarga lainnya) untuk mennyelesaikan tugas yang diberikan oleh guru pada saat pembelajaran jarak jauh seperti ini.

Menanamkan model SOLE (Self Organizing Learning Environment) pada peserta didik sangat mudah bagi guru karena guru hanya menjadi pengawas atas proses pembelajaran peserta didiknya, sedangkan peserta didik yang harus turut aktif dalam proses pembelajaran. Kesiapan peserta didik dalam mengikuti pembelajaran dengan menggunakan metode SOLE ini juga menjadi acuan dalam mengikuti pembelajaran. Tahapan-tahapan pada model pembelajaran SOLE ini membuat peserta didik berpikir kritis dan mendalam terhadap materi yang sedang mereka pelajari, dalam pembelajaran ini sifat kepekaan dan cermat dalam menganalisis suatu hal dapat mengacu pada pembentukan pola pikir setiap peserta didik. Sebab, peserta didik diminta untuk aktif dalam menjawab pertanyan-pertanyaan yang diberikan oleh guru. Menurut (Syaparuddin et al., 2020) Agar proses belajar aktif berjalan dengan yang diinginkan, guru sebagai penggerak belajar dan peserta didik dituntut untuk menggunakan pembelajaran aktif. Dengan begitu, bahwa berdasarkan analisis dari permasalahan analisis terhadap model pembelajaran SOLE dan kemandirian belajar peserta didik, dikatakan bahwa SOLE dapat meningkatkan kemandirian belajar dan keefektifan belajar pada siswa, karena siswa yang dintuntun berperan aktif dalam proses pembelajaran.

\section{SIMPULAN DAN SARAN}

Model pembelajaran SOLE (Self Organizing Learning Environment) ialah model pembelajaran yang menitik beratkan pada kemandirian peserta didik, untuk melatih kemandirian dan pola pikir yang baik dalam proses berpikirnya. Penerapan pembelajaran dengan menggunakan model SOLE akan berdampak baik untuk peserta didik dalam mencari pengetahuan baru dan menyelesaikannya secara mandiri pada materi akan dipelajari nantinya yang akan memperluas pengetahauannya secara mandiri. Dan keefektifan pembelajaran SOLE pada peserta didik baik, sebab progress kedepannya yang akan didapatkan peserta didik baik dan proses pembelajaran yang diciptakan oleh guru akan berjalan dengan efektif, karena ketercapaiannya indicator pembelajaran pada setiap peserta didik yang didapatkannya maksimal sesuai dengan kriteria ketuntasan minimal (KKM). 
Fahira.A; Amalia.N (2021). Pembelajaran SOLE dalam Membangun Keefektifan Belajar pada Peserta

Didik. Edudikara: Jurnal Pendidikan dan Pembelajaran, 6(3), 152-157.

\section{REFERENSI}

Arifa, F. N. (2020). TANTANGAN PELAKSANAAN KEBIJAKAN BELAJAR DARI RUMAH DALAM MASA DARURAT COVID-19. Vol. XII,. https://berkas.dpr.go.id/sipinter/files/sipinter-630-98920200707165734.pdf

Firdaus, F. M., Pratiwi, N. A., Riyani, S., \& Utomo, J. (2021). Meningkatkan kemandirian belajar peserta didik sekolah dasar menggunakan Model SOLE saat pandemi Covid-19. 12(1), 1-8. https://doi.org/https://doi.org/10.21831/foundasia.v12i1.37786

Kusasi, A., \& Satui, S. M. A. N. (2021). Penggunaan Model SOLE untuk Meningkatkan Hasil Belajar Daring Peserta Didik Materi Teori Kinetik Gas. 5(2). https://doi.org/https://doi.org/10.20527/jipf.v5i2.2833

Nyoman, N., \& Wati, K. (2021). Implementasi Model Pembelajaran Self Organized Learning Environments Berbasis Tri Kaya Parisudha untuk Meningkatkan Hasil Belajar Mahasiswa. 2(1), 1-10. urnal.stahnmpukuturan.ac.id/index.php/edukasi/article/view/1387/1085

Rosyid, D. M., \& Ekowanti, M. L. (2018). Pendidikan Bagi Generasi Emas Indonesia Abad 21: Sebuah Agenda Perubahan Paradigmatik. Proceedings of the ICECRS, 1(3), 113-118. https://doi.org/10.21070/picecrs.v1i3.1386

Saleh, M. (2020). Merdeka Belajar di Tengah Pandemi Covid-19. Prosiding Seminar Nasional Hardiknas, 1, 51-56. http://proceedings.ideaspublishing.co.id/index.php/hardiknas/article/view/8

Sole, F. B., \& Anggraeni, D. M. (2018). Inovasi Pembelajaran Elektronik dan Tantangan Guru Abad 21. Jurnal Penelitian Dan Pengkajian IImu Pendidikan: E-Saintika, 2(1), 10. https://doi.org/10.36312/esaintika.v2i1.79

Syaparuddin, S., Meldianus, M., \& Elihami, E. (2020). Strategi Pembelajaran Aktif Dalam Meningkatkan Motivasi Belajar PKn Peserta Didik. MAHAGURU: Jurnal Pendidikan Guru Sekolah Dasar, 2(1), 3142. https://ummaspul.e-journal.id/MGR/article/download/326/154

Syarifudin, A. S. (2020). Impelementasi Pembelajaran Daring Untuk Meningkatkan Mutu Pendidikan Sebagai Dampak Diterapkannya Social Distancing. Jurnal Pendidikan Bahasa Dan Sastra Indonesia Metalingua, 5(1), 31-34. https://doi.org/10.21107/metalingua.v5i1.7072

Wati, N. N. K. (2020). Perangkat pembelajaran berbasis E-learning di sekolah dasar. PINTU:Pusat Penjaminan Mutu, 1(2), 180-189.

http://stahnmpukuturan.ac.id/jurnal/index.php/jurnalmutu/article/view/913 